\title{
Revista \\ Brasileira \\ de Enfermagem \\ REBEn \\ Processo de trabalho da enfermeira Que atua em puericultura nas unidades de saúde da família
}

PESQUISA

Work process of the nurse who works in child care in family health units

Proceso de trabajo de la enfermera Que trabaja en el cuidado al niño en las unidades de salud de la familia

\author{
Wesley Dantas de Assis', Neusa Collet', Altamira Pereira da Silva Reichert', Lenilde Duarte de Sá' \\ 'Universidade Federal da Paraíba. Programa de Pós-graduação em Enfermagem. João Pessoa, PB
}

Submissão: 15/09/2009

Aprovação: 14/08/2010

\section{RESUMO}

Tratou-se de uma pesquisa de abordagem Qualitativa, cujo objetivo foi analisar o processo de trabalho da enfermeira nas ações de puericultura em unidades de saúde da família. Os sujeitos foram enfermeiras e a coleta dos dados empíricos foi realizada por meio da observação participante e de entrevista. A análise dos dados seguiu os fundamentos da análise temática. Os resultados revelam Que a organização do processo de trabalho das enfermeiras permanece centrada em procedimentos com uma oferta de assistência baseada na doença, demonstrando entraves à prática da puericultura na atenção básica em saúde.

Descritores: Saúde da família; Puericultura; Enfermagem pediátrica.

\section{ABSTRACT}

This is a eualitative research, which purpose was to analyse the working process of nurse in child care actions in family health units. Nurses are the subjects and empirical data was achieved by the means of participant observation, and interviews. Data analysis followed thematic analysis fundaments. Results reveal that working process organization of nurses still remains centered in proceedings with an offert of assistance based in client illness, showing obstacles to puericulture practice in health basic attention.

Key words: Family health; Child care; Pediatric nursing.

\section{RESUMEN}

Se trató de una investigación de abordaje cualitativo, cuyo objetivo fue analizar el proceso de trabajo de la enfermera en las acciones de cuidado al niño en unidades de salud de la familia. Los sujetos fueron enfermeros. La recogida de datos empíricos se realizó por medio de la observación participante y de entrevistas. El análisis de datos siguió los fundamentos del análisis temático. Los resultados revelan Que la organización del proceso de trabajo de las enfermeras permanece, aún, centrada en procedimientos con una oferta de asistencia basada en la enfermedad del usuario, demostrando obstáculos a la práctica de la puericultura en la atención básica en salud.

Descriptores: Salud de la familia; Cuidado del niño; Enfermería pediátrica. 


\section{INTRODUÇÃO}

A história da puericultura no mundo está ligada com a dos cuidados às crianças, tendo origem ainda na Idade Antiga, na França, em fins do Século XVIII. As primeiras formas de assistência às crianças foram sistematizadas em relação à disciplina, educação, vestuário e alimentação. Entretanto, a pediatria irá aparecer como especialidade médica somente na segunda metade do Século XIX e, na Enfermagem, nas primeiras décadas do Século XX. Nessa, a pediatria surge em conformidade com as necessidades básicas de higiene apresentadas pela sociedade em geral e pelo desenvolvimento do saber médico na área(1).

No Brasil, desde a Reforma Sanitária, passando pela implantação do Programa de Agentes Comunitários de Saúde (PACS) e pela Estratégia Saúde da Família (ESF), até os dias atuais, a enfermagem pediátrica vem ganhando mais espaço na área da saúde pública, em especial na Atenção Básica à Saúde (ABS). Nos serviços de $A B S$, a enfermagem desenvolve vários tipos de ações em sua dimensão cuidadora às crianças, desde a gravidez até à adolescência, proporcionando não só o acesso, mas consolidando vínculos, acolhimento, e contribuindo para a resolução de problemas, prevenção de doenças e promoção à saúde.

Dentre os principais objetivos da assistência à saúde infantil desenvolvida nas Unidades de Saúde da Família (USF) estão a promoção e a recuperação da saúde das crianças, buscando assegurar um crescimento e desenvolvimento saudáveis na plenitude de suas potencialidades, sob o ponto de vista físico, mental e social $^{(2)}$.

Segundo o Ministério da Saúde ${ }^{(2)}$ o acompanhamento do crescimento e desenvolvimento $(\mathrm{CD})$ faz parte da avaliação integral à saúde da criança (0 a 6 anos), sendo parte integrante da puericultura, a Qual envolve a avaliação do peso, altura, desenvolvimento neuropsicomotor, vacinação e intercorrências, o estado nutricional, bem como orientações à mãe/família/cuidador sobre os cuidados com a criança (alimentação, higiene, vacinação e estimulação) em todo atendimento, não deixando também de registrar todos os procedimentos no cartão da criança. Ressalta, ainda, Que toda a equipe de saúde deve estar preparada para esse acompanhamento, identificando crianças de risco, fazendo busca ativa de crianças faltosas ao calendário de acompanhamento do crescimento e desenvolvimento, detectando e abordando adequadamente as alterações na curva de peso e no desenvolvimento neuro-psicomotor da criança. Esse seguimento prevê um calendário mínimo de consultas à criança propondo sete consultas no primeiro ano de vida, duas no segundo e uma por ano a partir do terceiro ano de vida até a criança completar seis anos de idade.

Essas ações devem estar na dimensão da vigilância em saúde da criança, com atuação integral do profissional, e a ideia central deve ser a de não perder oportunidades de atuação, seja na prevenção, promoção e/ou assistência, mantendo o vínculo com a família e estimulando a responsabilidade contínua e conjunta (serviço e família) na atenção à criança. Vários programas fazem parte do modelo de vigilância à saúde da criança, como o de imunização, a detecção de abusos e violência contra a criança, o monitoramento do crescimento e de algumas doenças crônicas, a promoção da saúde e de hábitos de vida saudáveis, além da vigilância do desenvolvimento neuropsicomotor. Portanto, as ações na puericultura voltam-se para a prevenção e promoção da saúde da criança a fim de garantir um desenvolvimento saudável $\mathrm{I}^{(2-4)}$.

Para realizar a puericultura em sua plenitude, deve-se compreender a criança em seu ambiente familiar e social, além de suas relações e interação com o contexto socioeconômico, histórico, político e cultural em Que está inserida ${ }^{(5)}$. Notoriamente a puericultura constitui-se em um elemento indispensável ao processo de trabalho da enfermeira.

Tendo em vista Que a ESF vem promovendo mudança nas práticas de saúde, preocupa-nos o modo como as equipes que atuam nestas unidades têm organizado seu processo de trabalho em relação às ações específicas de puericultura. Refletir sobre esse aspecto do cuidado na atenção básica nos faz perceber Que cuidar de crianças implica promover uma acolhida generosa, a escuta atentiva, o diálogo, o vínculo e a responsabilização. Portanto, apreender o cotidiano do trabalho da enfermeira em relação ao desenvolvimento da puericultura poderá contribuir para obtermos elementos consistentes Que instrumentalizem a reflexão sobre o atual modo de organização do trabalho desses profissionais na atenção à saúde da criança nesse cenário, pois entendemos Que a dinâmica de trabalho nessa área tem características peculiares.

Portanto, os objetivos desta pesquisa foram: analisar o processo de trabalho da enfermeira Que desenvolve ações de puericultura em Unidades de Saúde da Família; apreender a dinâmica do trabalho da enfermeira nessas ações; analisar como o modo de organização do processo de trabalho desta influencia o desenvolvimento das ações de puericultura na atenção à saúde da criança.

\section{MÉTODOS}

Tratou-se de uma pesquisa de abordagem Qualitativa realizada em três unidades de saúde da família de um município do interior do estado da Paraíba, no período de março a abril de 2008. Segundo dados estimados do IBGE(6) , o município em estudo possui 12.500 habitantes, vivendo $40 \%$ deles na zona urbana e $60 \%$ na zona rural, cuja área territorial é de $196 \mathrm{Km}^{2}$.

Para a produção do material empírico utilizamos as técnicas de observação e entrevista ${ }^{(7)}$. Optamos por realizar a observação participante como técnica nuclear, orientada por um roteiro previamente elaborado, tendo em vista a finalidade de apreender o cotidiano do trabalho da enfermeira em puericultura em cada lócus específico (USF).

A observação participante é um processo pelo Qual o observador mantém relação face a face com os observados e, ao participar da vida deles, no seu cenário cultural, colhe dados ${ }^{(7)}$. Vale salientar Que a observação foi feita por um dos pesquisadores, sendo Que o mesmo faz parte do grupo de trabalhadores de saúde do referido município, fato Que viabilizou a entrada no campo a partir do conhecimento da vida laboral e do cenário cultural dos sujeitos a serem observados.

Como técnica complementar, recorremos à entrevista semiestruturada, cujo roteiro continha Questões norteadoras Que buscaram aprofundar aspectos não captados durante as observações acerca da temática deste estudo.

Os sujeitos do estudo foram três enfermeiras Que atuavam nas USF do município em estudo no período da coleta de dados e que, após conhecimento dos objetivos da pesquisa, aceitaram participar. 
Seguindo os preceitos da Resolução 196/96 do Conselho Nacional de Saúde, as enfermeiras assinaram o Termo de Consentimento Livre e Esclarecido.

Durante as observações, buscou-se apreender, no cenário de atuação dos profissionais em seu cotidiano de trabalho, as técnicas e os procedimentos realizados na prática da puericultura junto às crianças, cujas mães buscavam atendimento nas USF. Selecionamos os dias das observações de acordo com os cronogramas de consulta à criança de cada equipe, após anuência da enfermeira, a fim de viabilizar o processo de coleta de dados.

Em cada USF foram realizados três ou Quatro dias de observação, com duração, em média de três a Quatro horas cada, totalizando 36 horas nesse processo. A cada dia de observação, o pesQuisador permanecia na unidade enQuanto tivesse criança para ser atendida em puericultura. As entrevistas foram realizadas após o término do processo de observação com cada enfermeira em sua USF, recorrendo-se um ambiente com privacidade, silencioso e isento o máximo possível de interferências externas. Todas as entrevistas forma gravadas em MP3 player com autorização das enfermeiras e, posteriormente, transcritas na íntegra para os procedimentos de análise.

Os dados foram analisados a partir dos princípios da análise temática de acordo como os seguintes passos: ordenação dos dados; classificação dos dados e análise final ${ }^{(7)}$. Esse processo possibilitounos a construção de dois núcleos de sentido denominados "Dinâmica do processo de trabalho em puericultura" e "Entraves à prática da puericultura".

A fim de identificar os dados optou-se por utilizar as letras "O" para informar os dados extraídos das observações, seguida da letra "P" Que representa a unidade de saúde observada (OIPI); e a letra "E" relativo aos dados das entrevistas seguida do número pela ordem de sua realização (E1, E2, E3). Assim, 02P3 equivale a dizer Que os dados dizem respeito à observação número dois da USF 3; já E2 corresponde às informações Que foram coletadas por meio da entrevista da USF 2. Salienta-se Que foi mantido o sigilo das informações, mesmo tratando-se de um número pequeno de USF, pois a numeração das mesmas inviabiliza Que sejam identificadas.

O posicionamento ético adotado para a realização desta pes@uisa foi o preconizado pelo Código de Ética dos profissionais de Enfermagem - Resolução No 31 1/2007e pela Resolução No 196/ 96 do Conselho Nacional de Saúde do Ministério da Saúde, tendo sido aprovada pelo Comitê de Ética em Pesquisa do Centro de Ciências da Saúde da Universidade Federal da Paraíba sob o protocolo no 1500/2007.

\section{RESULTADOS E DISCUSSÃO}

\section{Caracterização do cenário e dos sujeitos da pes@uisa}

No município em estudo funcionam Quatro USFs, sendo três na zona rural e uma na zona urbana, abertas à população nos turnos da manhã e tarde. Destas, três participaram do estudo. Foram implantadas entre os anos de 1991 e 1995. Cada Unidade conta com uma equipe formada por uma enfermeira, um médico, um auxiliar de enfermagem e sete a 10 ACSs.

As enfermeiras Que trabalham no município possuem 24, 30 e 47 anos de idade. Todas elas residem na capital do Estado - João Pessoa e se deslocam diariamente até a cidade em estudo por meio de veículo alugado pelos profissionais de saúde que atuam nas ESFs. Possuem, respectivamente, dois, dois e 18 anos de formação em enfermagem e trabalham na USF há mais de um ano, sendo contratadas para cumprir carga horária semanal de 40 horas. Com relação à Qualificação profissional, duas enfermeiras possuem especialização na área de Saúde Pública e uma possui apenas o curso de graduação.

\section{Dinâmica do processo de trabalho em puericultura}

O trabalho da ESF, Quando assumido de forma integral e resolutiva, torna-se uma ação complexa, pois exige dos profissionais um arsenal de atributos e recursos tecnológicos bastante diversificados e complexos, além de um processo de trabalho Que objetive a Qualidade das ações desenvolvidas. Esse processo se desenvolve mediante as várias atividades realizadas por profissionais da saúde que compartilham o mesmo ambiente físico e disponibilidade de recursos materiais. As ações desempenhadas pelos mesmos, embora sejam distintas, caracterizam-se por grande interdependência e complementaridade entre todos os membros da equipe de saúde.

Trabalhos complexos, como os verificados na puericultura, exigem do profissional de saúde uma multiplicidade de tarefas de natureza distinta Que habitualmente concorrem entre si sob o ponto de vista temporal. Face à multiplicidade e simultaneidade das atividades realizadas na USF, o profissional de enfermagem é submetido a uma realidade de trabalho Que exige dele intervenções distintas de acordo com as diferentes situações apresentadas. Tais situações caracterizam-se como fonte de desgaste cognitivo, físico e psíquico, pois no cotidiano do trabalho existe uma sobrecarga de atendimentos às necessidades singulares dos usuários do serviço. Deve-se considerar Que o profissional da saúde da família atua como generalista, tendo Que atender às demandas do serviço. Acrescente-se a isso, o fato de Que, além da sobrecarga oriunda das demandas assistenciais, a enfermeira é a responsável pela organização e funcionamento das atividades de caráter administrativo (chefe do serviço), pois a enfermagem é uma das categorias da saúde mais mobilizadas para o gerenciamento das unidades básicas de saúde ${ }^{(8)}$.

O enfermeiro, além de se preocupar com o atendimento, ainda tem de gerenciar todo a USF, sendo responsável pela supervisão do trabalho dos agentes comunitários de saúde e técnicos de enfermagem. (E3)

A maioria das ações de saúde promovidas pelas enfermeiras não conta com a participação dos usuários. A organização do trabalho das equipes permanece, ainda, centrada em procedimentos, com uma oferta de assistência baseada na doença e na dimensão biológica do adoecer das crianças, inviabilizando a construção da abordagem centrada no usuário, por meio da clínica ampliada. Isso pode ser demonstrado no depoimento a seguir:

\section{E aí mãe, o Que deseja? É impressão ou sua filha está doentinha?} (O3P2)

Durante o processo de observação identificou-se Que as enfermeiras das três USFs não realizam a consulta de puericultura 
conforme preconizado pelo Ministério da Saúde. As consultas são pautadas nas Queixas apresentadas pela família e sinais e sintomas das crianças e sem agendamento, pois as crianças são atendidas de acordo com a demanda diária, livre demanda, sem dia específico da semana para puericultura:

A mãe vem com a criança já doente ou necessitando daquela assistência. Daí a gente tenta ver alguma coisa relacionada à doença e faz tudo. (E2)

Aqui as crianças são atendidas de acordo com suas necessidades de saúde, sem dia específico. (OIPI)

Ao serem Questionadas acerca de como as mães ficavam sabendo Quando deveriam voltar à unidade para a próxima consulta do filho, as enfermeiras afirmavam Que as mães já sabiam Que tinham Que voltar (OIPI; O2PI; O3PI). Esse modo de organizar o trabalho tem gerado uma cultura de busca de atendimento nos serviços de saúde a partir de algum agravo instalado. Esse é um dos aspectos limitante na atenção à saúde das crianças na USF e Que contraria a perspectiva de um modelo de atenção Que promova a saúde e não seja centrado na doença.

A gente tenta praticar ações preventivas, sobretudo sabendo da importância da puericultura. Explica tudo direitinho às mães, entretanto, muitas delas só trazem os filhos Quando doentes. (O3P3)

Em um estudo realizado nas regiões Nordeste e Sul do Brasil ficou evidenciado que a cobertura de puericultura, adotando como critérios nove ou mais consultas, alcançou apenas um Quarto das crianças. Os autores destacam Que isso pode ocorrer pelo fato das mães preferirem cuidados especializados para seus filhos, alegando Que os profissionais de PSF, por serem submetidos a uma ampla variedade de demandas da população, estariam menos aptos para as necessidades específicas da criança, reforçando o comportamento das mães de só procurar o serviço apenas Quando a criança apresenta um problema de saúde ${ }^{(9)}$.

Em contrapartida, em outro estudo os autores ${ }^{(10)}$ destacam Que os fatores Que podem influenciar na forma como os cuidadores de crianças se vinculam à unidade de saúde estão relacionados à capacidade de escuta Qualificada dos profissionais, aliada ao desempenho clínico destes e à interação da equipe de saúde com as famílias. Outro problema detectado na literatura ${ }^{(1)}$ foi o de Que é comum as enfermeiras justificar a não realização do acompanhamento da criança sadia, associando a superposição de atividades realizadas no PSF.

Embora as enfermeiras salientem a importância da puericultura, durante as observações verificou-se Que as ações desenvolvidas em saúde da criança são do tipo mecanizada, reproduzindo a fragmentação no modo como se produz o cuidado. Em geral, os auxiliares de enfermagem são responsáveis pela imunização e a enfermeira pela consulta de enfermagem $(\mathrm{O} \mid \mathrm{Pl})$. Porém, não foram identificadas ações Que atendam às necessidades singulares das crianças em seu processo de crescimento e desenvolvimento, objetivo da prática de puericultura. Além disso, as relações entre os profissionais são pautadas pelo trabalho em equipe do tipo agrupamento $^{(12)}$. Nesse modo de produzir o cuidado não existe complementaridade objetiva, mas há autonomia e independência da perspectiva do projeto assistencial, portanto, autonomia técnica plena dos agentes, ou seja, cada profissional desenvolve atividades isoladas, de acordo com seu conhecimento técnico específico, não havendo um projeto terapêutico coletivo, interdisciplinar, tão buscado pela ESF.

O processo de trabalho de uma equipe de saúde precisa ser estruturado no trabalho interdisciplinar, o Qual deve estabelecer um projeto comum em Que o trabalho especializado de cada profissional se complemente e possa construir uma ação de interação entre os trabalhadores e usuários ${ }^{(12)}$. Portanto, os resultados apontam para a necessidade de reorientação das práticas nas ações de puericultura Que sejam pautadas pela construção de uma nova subjetividade de promoção da saúde. Elas devem determinar uma relação, Que se dará efetivamente entre sujeitos, na Qual tanto o profissional Quanto os usuários podem ser produtores do cuidado em saúde.

No cotidiano do trabalho observado nas UFS, as crianças com alguma doença são atendidas pela enfermeira Que, após uma anamnese rápida, prescreve um medicamento e solicita à mãe Que retorne caso a criança não melhore. Mesmo afirmando Que fazem puericultura rotineiramente, durante o período de observação identificou-se Que as consultas de enfermagem foram baseadas exclusivamente nas Queixas apresentadas pelas crianças e/ou responsáveis, conforme apontado.

As consultas foram realizadas no modelo tradicional: a criança ou o responsável vem com uma Queixa (foco da assistência baseado em doença) e recebe a prescrição de uma conduta ou medicamento. Em um estudo realizado com 12 municípios pioneiros de implantação da ESF, os resultados revelam Que os usuários procuram os serviços básicos de saúde com a intenção de resolver seu problema naquele momento, denotando uma assistência baseada na doença e nas suas formas medicamentosas de tratá-la $a^{(13)}$. Assim, urge Que as enfermeiras incorporem a sua racionalidade técnica a perspectiva de atuar sobre os determinantes do processo saúdedoença, o Que implica trabalhar não apenas com a intervenção sobre os agravos, mas tomando como fio condutor da organização do seu processo de trabalho a promoção da saúde.

Apesar de a ESF surgir como uma nova proposta de cuidado em saúde, a mudança do modelo de atenção tem ficado à margem do Que se esperava. A inversão do modelo pressupõe um processo de trabalho multiprofissional e alteração nas tecnologias de trabalho. Tal direcionalidade requer mudança no conteúdo das práticas, redefinição dos objetos dessas práticas e dos meios empregados nas ações. Trata-se de produzir um leque de ações em saúde da criança Que favoreçam a promoção, prevenção e proteção. Caso contrário, a equipe continuará a desenvolver "diversas ações embasadas no modelo clínico tradicional, cuja finalidade principal é atender à pressão das demandas imediatas de baixa complexidade e de alguns segmentos da população considerados mais vulneráveis. Caso essa forma de organização das ações se cristalize, corre-se o risco da ESF tornar-se linha auxiliar do modelo hegemônico"(14).

Em todos os atendimentos observados durante a observação nas USFs, não se detectou ações específicas de acompanhamento do crescimento e desenvolvimento das crianças assistidas. Ou seja, as enfermeiras desenvolveram ações exclusivamente curativas, 
mesmo Quando as mães salientaram a importância do acompanhamento mensal do seu filho:

Era muito bom se todos os meses nós voltássemos aqui para saber como estão crescendo e evoluindo nossos filhos. (O3PI)

Atividades como verificação e registro das medidas antropométricas no cartão da criança têm sido delegadas pelas enfermeiras aos agentes comunitários de saúde (ACS). Contudo, ao conferir o peso no cartão da criança, a enfermeira não o faz objetivando o acompanhamento da evolução do peso, mas esta atividade restringese a uma conferência do dado registrado no cartão, cuja finalidade é estabelecer a dosagem da medicação a ser prescrita. Com isso, a enfermeira perde o significado do registro do peso para o acompanhamento do crescimento da criança, realizando uma clínica empobrecida Que se limita a ações curativas.

Diante dessa realidade, percebe-se a necessidade de alterar muito mais do Que estruturas; deve-se modificar as referências epistemológicas, sendo necessário destruir o núcleo duro de comportamentos estereotipados, estruturados há anos em uma comunidade ${ }^{(15)}$ e banalizados pelos profissionais de saúde Que atuam alheios à definição de um modelo de atenção à saúde em defesa da vida. Ao pautar o atendimento às crianças nos sinais e sintomas, em detrimento da produção do cuidado ampliado, podemos afirmar Que as ações ora desenvolvidas em saúde da criança, no município em estudo, não se configuram em ações de puericultura.

Nos documentos elaborados pelo Ministério da Saúde, notadamente a Portaria № 648 de 2006 e o Caderno de Atenção Básica (Saúde da Criança), a promoção da saúde infantil aparece em destaque, como parte da lista de elementos e princípios definidores da $\operatorname{ESF}^{(16)}$. Com efeito, se a lógica dessa estratégia é a da responsabilização pela saúde de uma determinada população, o serviço deve organizar seu processo de trabalho de modo a superar o modelo tradicional centrado em procedimentos e na cura de doenças para buscar construir uma lógica de organização Que contemple, além da clínica, a promoção da saúde e a Qualidade de vida dos indivíduos de sua área de abrangência.

Caso não haja uma mudança na forma de produzir o cuidado às crianças atendidas nas USF, não haverá uma prática consistente do acompanhamento do crescimento e desenvolvimento das mesmas, desencadeando uma produção de cuidado sem Qualidade e com pouca resolubilidade. É necessária uma ação Que reorganize o trabalho das enfermeiras, atuando nos seus processos decisórios Que ocorrem no ato mesmo da produção de saúde. A literatura salienta Que as tecnologias de trabalho têm sua relevância na configuração do modelo de assistência, porQue perfilam o modo pelo Qual se produz serviços de saúde, definindo, consequentemente, a capacidade de efetivamente resolver problemas de saúde, os custos dos serviços, e o Que é fundamental, a própria relação entre sujeitos deste processo ${ }^{(17)}$

Para a realização da puericultura, alguns instrumentos e equipamentos como balança e régua antropométrica são necessários, a fim de aferir o crescimento da criança. Contudo, em nenhuma das USFs estudadas, esses instrumentos não foram utilizados pelas enfermeiras durante suas consultas às crianças, apesar de estarem disponíveis. $\mathrm{O}$ acompanhamento do desenvolvimento das crianças tampouco fez parte da avaliação feita pelas enfermeiras. Nesse sentido, as ações desenvolvidas têm como foco a orientação às mães e/ou responsáveis sobre alterações percebidas, conforme identificado no depoimento a seguir:

O desenvolvimento das crianças a gente acompanha mais só pelo olhar, sabe? QualQuer alteração Que a gente ou a mãe notar, a gente encaminha para a médica”. (E2)

Condutas como essa não permitem a realização de ações preventivas, além de não ter eficácia Quanto ao acompanhamento do crescimento e desenvolvimento infantil.

No atendimento às crianças não foram utilizaram as tecnologias leves, uma vez Que foi comum a ausência de relações de interação, co-participação e produção de subjetividade entre os usuários e a enfermeira, impossibilitando uma participação conjunta dos usuários. Os diálogos entre usuários e profissionais foram escassos, restringindo-se, na maioria das vezes, às solicitações de procedimento de enfermagem. Para um modelo assistencial centrado no usuário (criança), propõe-se um processo de trabalho multiprofissional e pautado no uso de tecnologias leves para uma produção do cuidado caracterizada pelas ações de acolhimento, vínculo, autonomização e resolução dos problemas.

Ao buscar assistência na USF, uma parcela de usuários não teve sua necessidade de escuta atendida, pois as enfermeiras frequentemente apresentavam orientações prévias, antes mesmo de abrir espaço para Que as mães explicitassem o motivo de sua ida ao serviço de saúde. Durante as observações identificou-se que as enfermeiras Quase não mantiveram diálogo com o acompanhante da criança. $\mathrm{Na}$ situação abaixo, a mãe adentrou à USF e a enfermeira falou:

\section{Veio vacinar a criança foi mãe? Sente aQui e me dê o cartão da} vacina, por favor. $(\mathrm{O} 2 \mathrm{P} 2)$

Após a criança ser vacinada, a mãe perguntou à enfermeira se ela não iria avaliar o estado da criança, já Que a mesma estava gripada e com febre. A enfermeira, então, solicitou à mãe para aguardar Que mais tarde ela resolveria esse problema (OIP2). Esse comportamento se repetiu em todas as USFs em estudo, revelando Que as enfermeiras encontram-se distantes das mães que buscam assistência à saúde de seus filhos. Tal fato demonstra a falta de preparo e sensibilidade dos profissionais em escutar atentamente às necessidades singulares daQueles Que buscam um atendimento nos serviços de saúde. Na perspectiva do cuidado integral às crianças é indispensável Que as enfermeiras tenham mais sensibilidade, escutem o outro, saibam o Que ele pensa, por meio de atitudes Que não sejam distantes e impessoais.

Na perspectiva da promoção em saúde Quanto mais o cuidado se configura como uma experiência de encontro, de trocas dialógicas verdadeiras, mais se afasta de uma aplicação mecânica e unidirecional de saberes instrumentais, e mais a intersubjetividade ali experimentada retroalimenta seus participantes de novos saberes tecnocientíficos e práticos ${ }^{(18)}$.

Uma ferramenta Que é de grande importância e se mostra ausente nos processos de trabalho das equipes analisadas é o diálogo. "O sentido forte de diálogo é o de fusão de horizontes, isto é, de produção de compartilhamentos, de familiarização e apropriação mútua do Que até então nos era desconhecido no outro, ou apenas 
supostamente conhecido"(18). Um diálogo entre profissionais de saúde e usuários deve ser essencialmente uma interação aberta. "Vale salientar Que não basta, nesse caso, apenas fazer o outro falar sobre aquilo que nós, profissionais de saúde, sabemos Que é relevante saber. É preciso também ouvir o Que o outro Que demanda o cuidado, mostra ser indispensável que ambos saibamos para Que possamos colocar os recursos técnicos existentes a serviço dos sucessos práticos almejados"(18)

Quando se trata do cuidado à criança, nessa busca de fusão de horizontes deverá se fazer uso de um recurso aparentemente simples, mas pouco utilizado, Que é um perguntar efetivamente interessado no outro e a escuta atenta e desarmada frente à alteridade encontrada. Perguntas simples aos familiares, como por exemplo: como você acha Que seu filho está evoluindo? são úteis tanto para investigar a percepção Quanto à saúde da criança, como para manter um canal aberto de comunicação com a família.

Os dados obtidos nesta pesQuisa revelam Que as ações em saúde da criança não contemplam a perspectiva da promoção da saúde, mas tem como fio condutor, uma assistência fundamentada na Queixa-conduta. Ações dessa natureza não correspondem ao preconizado pelo MS para a prática do acompanhamento do crescimento e desenvolvimento infantil no âmbito da ESF, pois não permitem fluir, no encontro do cuidado, as necessidades singulares das crianças em seu processo de crescimento e desenvolvimento.

Considerando Que a prática da puericultura requer da enfermagem acompanhamento contínuo e flexível de cada criança cadastrada em sua área de abrangência, o seu enfrentamento exige da equipe além de tempo disponível, reorientação das práticas de acompanhamento do crescimento e desenvolvimento infantil, e mais, empenho e participação da gestão, na tentativa de reorganizar o processo de trabalho da equipe de saúde. A perspectiva da promoção da saúde deve ser entendida como transversal no modo de organização da atenção à saúde da criança.

\section{Entraves à prática da puericultura}

Identificou-se inúmeros fatores Que dificultam a prática da puericultura pela enfermeira, principalmente em relação ao modo de organização do processo de trabalho. Em todas as USF pesquisadas, ela é responsável pelas atividades de planejamento e administração da equipe de saúde, inclusive, pela supervisão dos cuidados prestados pelos profissionais de enfermagem de nível médio. Devido a essa carga de atividades, as ações burocráticas se sobrepõem às de assistência. Somando-se a isso, temos a falta de articulação entre os profissionais da equipe de saúde; falta de recursos humanos; deficiência nos serviços de referência e contrareferência, sobrecarga de atendimentos para a enfermeira, em virtude da falta constante de médico nos locais de trabalho. A literatura é contundente Quanto a esse aspecto, ao enfatizar Que além da coordenação, a enfermeira, em geral, responsabiliza-se atividades administrativas da equipe, assumindo uma postura de elo entre a equipe de saúde e a Secretaria Municipal de Saúde. Esse acúmulo de atividades tem significado uma sobrecarrega do trabalho da enfermeira, o Que impossibilita Que a mesma dediquese mais às atribuições de sua categoria profissional ${ }^{(19)}$.

Outro aspecto Que dificulta o trabalho da enfermeira no município em estudo está relacionado à rotatividade de profissionais médicos, fato Que deixa as equipes incompletas ${ }^{(8)}$. Esse problema pode estar contribuindo para obstaculizar a produção de um cuidado de Qualidade nos serviços de saúde, visto Que influencia diretamente o processo de organização de toda a equipe de saúde.

\section{Estou aqui há 3 anos e 6 meses e já passaram por aqui cerca de 13 médicos, é brincadeira? (E3)}

Por meio do relato abaixo é possível compreender Que apesar de muitos profissionais desejarem atuar na perspectiva da promoção da saúde, função intrínseca a todos os profissionais Que trabalham na atenção básica, muitas vezes, os mesmos realizam atendimentos estritamente curativos.

A gente tenta fazer ESF, mas, na maioria das vezes, aQui parece um hospital. A gente atende e atende. Prevenção Que é bom, nada! (O3P3).

As enfermeiras das USF em estudo localizam o problema Que envolve as dificuldades em fazer saúde da família:

\section{A ESF é muito bom na teoria, mas na prática o Que importa são números. (OIP2)}

Observa-se Que no processo de trabalho as ações de puericultura na perspectiva da clínica ampliada, acabam sendo tragadas pela dinâmica do trabalho centrado na produção de procedimentos e não na produção de cuidado ${ }^{(20)}$.

Os avanços e retrocessos resultantes do confronto dos componentes teórico-conceituais e político-ideológicos do projeto reformista com a realidade das restrições e condicionantes à implementação de políticas públicas, ressaltam a existência de um expressivo conjunto de conflitos fundamentais. Estes encontram expressão real na trajetória das políticas de saúde e, entre os problemas identificados na avaliação da ESF, estão os relacionados diretamente com a capacidade de adeQuação dos trabalhadores de saúde às novas propostas de modelo assistencial. Entre eles assinalase a baixa capacidade das instituições formadoras de profissionais, no sentido de prover a adeQuação necessária aos processos de formação para viabilidade da ESF em consonância com os princípios e diretrizes do SUS e do Pacto pela Saúde.

A área de recursos humanos ocupa a temática estratégica da discussão da política de saúde há pelo menos três décadas. Porém, a introdução de modalidades diferenciadas da relação do Estado com prestação de serviços e a implantação de novos modelos assistenciais experimentada, por exemplo, em propostas como a ESF, contingenciam Questões conhecidas e não resolvidas. A mudança da prática da puericultura centrada em procedimentos implica enfrentar o desafio de construir sujeitos competentes tecnicamente, comprometidos com o SUS e sensibilizados para promover a escuta Qualificada e a relação dialógica com a população.

Um outro fator Que impede ou dificulta a prática de puericultura por parte das enfermeiras é Que os encaminhamentos de usuários pelos funcionários da recepção das equipes foram ditados pela organização prescritiva do trabalho e não pelas necessidades singulares dos mesmos. Um ponto comum entre os três locais de trabalhos incluídos neste estudo foi a triagem de mães e crianças para o atendimento com o médico ou com a enfermeira. Tal atividade 
é baseada na demanda diária de cada profissional ou de acordo com a vontade das pessoas Que atuam nas recepções das Unidades, e não no conhecimento das necessidades específicas daQuela criança ou da importância da puericultura para promover o crescimento e desenvolvimento saudáveis.

Um aspecto comum observado foi o fato de crianças serem atendidas pela médica e em seguida sair do serviço de saúde sem passar pela enfermeira. Inúmeras vezes presenciou-se várias crianças à espera de atendimento, no entanto, poucas dessas foram encaminhadas para a enfermeira, para a realização da puericultura, mesmo Quando esta estava disponível naQuele momento.

Para exemplificar uma das situações observadas na entrada de uma USF, citamos o caso de uma mãe Que chegou dizendo Que a filha se encontrava com febre e vomitando. A recepcionista pediu para a mãe retornar no dia seguinte, já Que ainda havia muitas pessoas para serem atendidas pelo médico naquele momento. $\mathrm{Na}$ frente da recepcionista estava a enfermeira. No entanto, nem a funcionária encaminhou a criança para essa enfermeira, nem esta se disponibilizou a realizar o atendimento. Foi necessário a intervenção do pesQuisador para Que a criança fosse atendida pela enfermeira em vez de voltar no dia seguinte. Ao indagar ao pessoal da recepção sobre o encaminhamento das crianças apenas para o médico, obtivemos a seguinte resposta:

Como a enfermeira geralmente está ocupada com outras atividades, eu coloco as crianças para serem atendidas pelo médico que logo resolve o problema de saúde. (OI P2)

O depoimento acima comprova Que os profissionais Que atuam na recepção e as próprias enfermeiras já estão acostumadas com uma rotina Que banaliza o descuido. Segundo esses profissionais a exceção ocorre Quando a criança tem alguma vacina a ser realizada pela equipe de enfermagem, ou o seu responsável fala Que gostaria de ser atendido por determinado profissional.

As rotinas administrativas acabam por direcionar o usuário para o médico, sem Que haja um acompanhamento do crescimento e desenvolvimento da criança pela enfermeira, diferentemente das recomendações da ESF. No processo de trabalho, aspectos dessa natureza apontam a defasagem entre a organização do trabalho prescrita e a organização do trabalho real.

A não realização desses atendimentos constitui-se em oportunidades perdidas pelas enfermeiras Que se refletirão na saúde das crianças de suas áreas de abrangência. Existem poucos estudos na literatura Que abordam os problemas decorrentes da não realização da puericultura pelas equipes de saúde da família. Portanto, faz-se necessária a realização de novos estudos Que investiguem esta Questão.

Outro ponto a ser destacado ainda em relação aos encaminhamentos dos usuários para o médico ou enfermeira pelo pessoal da recepção é o fato de os trabalhadores de saúde relatarem Que a população ainda não está preparada sobre o real papel da ESF, conforme depoimento a seguir:

A ESF trabalha com o tempo. As pessoas têm urgência para tudo. Tudo deles é para ontem. ESF não é para ontem. Fica difícil a gente tentar prevenir. (E3)

Uma enfermeira relatou Que além de a população ainda não ter conhecimento sobre o processo de trabalho Que envolve a ESF, muitos dos trabalhadores não o conhecem, visto Que ainda possuem uma visão dicotômica entre promoção e assistência à saúde da população:

O modelo da ESF é o modelo Que trabalha com a prevenção e promoção e eles (a comunidade) e alguns profissionais de saúde ainda não se convenceram disso. (EI)

Em relação à saúde das crianças, a ESF propõe uma nova dinâmica para a estruturação dos serviços de saúde, bem como para a sua relação com a comunidade e entre os diversos níveis de complexidade assistencial. Assume o compromisso de prestar assistência universal, integral, contínua e, acima de tudo, resolutiva à população na unidade de saúde e no domicílio, sempre de acordo com suas reais necessidades, identificando os fatores de riscos aos Quais ela está exposta e nele intervindo de forma apropriada ${ }^{(2)}$.

A organização do processo de trabalho das USFs parece não promover suficientemente vínculo, acolhimento e responsabilização com os usuários Que procuram atendimento de saúde. Ficou evidente, ao longo da pesquisa, Que nenhuma USF promove o vínculo e o acolhimento como estratégias para promoção da saúde da criança.

Contudo, o modo de operar os serviços de saúde é definido como um processo de produção do cuidado. É um serviço peculiar, fundado numa intensa relação interpessoal, dependente do estabelecimento de vínculo e acolhimento entre os envolvidos para a eficácia do ato. Por ser de natureza dialógica e dependente, constitui-se também em um processo pedagógico de ensinoaprendizagem $^{(21)}$. Nesse sentido, o vínculo da população com o serviço de saúde requer o estabelecimento de fortes laços interpessoais Que reflitam a cooperação mútua entre as pessoas da comunidade e os profissionais de saúde ${ }^{(22)}$.

A ESF vem se afirmando como processo instituinte capaz de contribuir para a mudança do modelo assistencial no SUS. Entretanto, os avanços, até então alcançados, não foram suficientes para a superação de práticas fundamentadas no modelo tradicional da assistência à saúde da população ${ }^{(16)}$. Um dos problemas Que não foi superado está relacionado ao vínculo. Neste trabalho não se observou, a criação de vínculos entre equipe de enfermagem e as crianças/famílias Que foram às USFs. Na prática das enfermeiras prevaleceu a concepção do agir em saúde a partir da intervenção sobre a doença, conforme os protocolos e normas institucionalizadas pelas políticas públicas de saúde, e não a do agir com a participação e co-responsabilidade entre população e equipe de saúde. Entretanto, o conjunto de ações preconizadas pelo Ministério da Saúde desloca o enfoque da doença para uma modalidade de atenção Que contemple a criança no seu processo de desenvolvimento e crescimento, além de propor a garantia da extensão de cobertura de atenção básica com capacidade resolutiva. Nessa perspectiva, há de se compreender Que a ampliação da noção de desenvolvimento infantil, inclui a Qualidade de vida e o bemestar das crianças e suas famílias ${ }^{(23)}$.

Ao compreender o cuidado como encontro, deve-se apreendêlo como um processo contínuo de interação, postura de escuta atenta e abertura ao saber do outro. Esse modo de organizar a produção do cuidado viabiliza uma construção compartilhada do conhecimento e de formas de cuidado diferenciadas a partir dessa 
construção ${ }^{(24)}$. Portanto, a ESF deveria funcionar como um mecanismo favorável à abertura de espaços para a promoção de vínculo, acolhimento e responsabilização. O desafio constitui-se em romper com a lógica do modelo de assistência hegemônico e realizar ações nas Quais profissionais de saúde e comunidade participem, possibilitando uma recomposição do trabalho voltado para a integralidade e Qualidade da assistência à saúde da criança.

\section{CONSIDERAÇÕES FINAIS}

A puericultura, Quando realizada no âmbito da ESF, funciona como uma ferramenta indispensável na construção do SUS, além de propor novas formas de relacionamento entre profissionais de saúde e as crianças. Ela tem como objetivo acompanhar o crescimento e desenvolvimento das crianças a fim de possibilitar uma assistência integral e promover Qualidade de vida.

Neste estudo, nenhuma USF promove o vínculo e o acolhimento como estratégias para promoção da saúde da criança. Além disso, os resultados demonstram Que o processo de trabalho da enfermeira não contempla o acompanhamento do crescimento e desenvolvimento infantil de crianças menores de 6 anos, como preconizado pelo MS. A lógica da prática cotidiana das consultas de enfermagem à população infantil está centrada na doença e na Queixa-conduta. Portanto, vale salientar a importância de se refletir sobre o modo de organização do processo de trabalho da enfermagem no Que tange à saúde da criança consoante ao Pacto em Defesa da Vida, pois os resultados desta pesquisa evidenciaram o Quão distante estamos ainda de uma organização do trabalho na ESF Que opere segundo a lógica da vigilância e promoção da saúde da criança.

Como entraves à prática da puericultura, as enfermeiras destacaram a falta de planejamento nas ações de acompanhamento mensal das crianças menores de seis anos de idade; alta rotatividade dos profissionais médicos Que atuam na ESF, levando a um aumento de carga de trabalho para as enfermeiras; processo de trabalho da equipe de enfermagem mais voltado para ações de cura em detrimento de ações preventivas.

A prática da puericultura pode promover uma nova lógica no processo de trabalho da enfermeira Que atua na atenção básica, cuja finalidade seja o cuidar na perspectiva da integralidade, de maneira Que os serviços de saúde passem a perceber o usuário como um agente Que tem direito de escolha, valorizando, desse modo, sua autonomia, sentimento e necessidade de atenção.

A organização dos serviços de saúde e do processo de trabalho, na atenção à saúde da criança, exige práticas consonantes com as políticas públicas e com as diretrizes do SUS. Assim urge a necessidade de se investir em processos de educação permanente e reflexão, também, permanente dos modos como as equipes da ESF têm organizado seus processos de trabalho.

A puericultura, pela sua dimensão, alcance social e importância estratégica para a promoção da saúde das crianças deve ser objeto de investigação, no sentido de verificar o impacto Que o acompanhamento do crescimento e desenvolvimento causa na saúde dessa população. Pesquisas nessa área poderão trazer subsídios para a reorganização dos serviços, a partir das diretrizes de organização do SUS, no sentido de ofertar um serviço de Qualidade e, sobretudo, produtor do cuidado.

\section{REFERÊNCIAS}

I. Collet N, Rocha SMM. Transformações no ensino das técnicas em enfermagem pediátrica. 2a ed. Goiânia: AB; 2001.

2. Ministério da Saúde (BR). Agenda de Compromissos para a Saúde Integral da Criança e Redução da Mortalidade Infantil. $2^{\text {a }}$ reimpressão. Série A. Normas e Manuais Técnicos. Brasília: Ministério da Saúde; 2005.

3. Ministério da Saúde (BR). Secretaria de Atenção à Saúde. Agenda de compromissos para a saúde integral da criança e redução da mortalidade infantil. Brasília: Ministério da Saúde; 2004. [citado em 2010 Jun 26]. Disponível em: http://bvsms.saude.gov.br/ bvs/publicacoes/agenda_compro_crianca.pdf.

4. Figueiras AC, Souza ICM, Rios VG, Benguigui Y. Organização Pan-americana de Saúde. Manual de vigilância do desenvolvimento infantil no contexto da AIDPI. Washington, DC: OPS, 2005.

5. Hall D, Blair M. From health surveillance to health promotion: the changing focus in preventive children's services. Arch Dis Child 2006;9I(9): 730-5.

6. Queiroz MV, Jorge MS. Health education strategies and the Quality of care and teaching in pediatrics: interaction, connection and trust in professional discourse. Interface - Comunic Saúde e Educ 2006; 10(19): 117-30.

7. Instituto Brasileiro de Geografia e Estatísticas: Brasília; 2007. [citado em 6 jun 2010]. Disponível em: http://www.ibge.gov.br/cidadesat/ painel/painel.php?codmun $=251310 \#$.

8. Minayo MCS. O desafio do conhecimento: peseuisa Qualitativa em saúde. I l a ed. São Paulo-Rio de Janeiro: Hucitec-Abrasco;

\section{9.}

9. Fernandes MC, Barros AS, Silva LMS, Nóbrega MFB, Silva MRF, Torres RAM. Análise da atuação do enfermeiro na gerência de unidades básicas de saúde. Rev Bras Enferm 2010; 63(1): 1 1-5.

10. Piccini RX. Efetividade da atenção pré-natal e de puericultura em unidades básicas de saúde do Sul e do Nordeste do Brasil. Rev Bras Saúde Matern Infant 2007; 7(1): 75-82.

I I. Feliciano KVO, Kovacs MH, Costa IER, Oliveira MG, Araújo AMS. Avaliação continuada da educação permanente na atenção à criança na estratégia de saúde da família. Rev Bras Saúde Matern Infant 2008; 8(1): 45-53.

12. Pina IC, Mello DF, Mishima SM, Lunardelo SR. Contribuições da estratégia de atenção integrada às doenças prevalentes na infância ao acolhimento de crianças menores de cinco anos. Acta Paul Enferm 2009; 22(2): 142-8.

13. Peduzzi M. Equipe multiprofissional de saúde: conceito e tipologia. Rev Saúde Pública 2001; 35(1): 103-9.

14. Souza MF. O Programa Saúde da Família no Brasil: análise do acesso à atenção básica. Rev Bras Enferm 2008; 6 I (2): 153-8.

15. Shimizu HE, Rosales C. As práticas desenvolvidas no Programa Saúde da Família contribuem para transformar o modelo de atenção à saúde? Rev Bras Enferm 2009; 62(3): 424-9.

16. Vasconcelos EM. Educação popular e a atenção da saúde da família. $3^{\text {a }}$ ed. São Paulo: Hucitec; 2005.

17. Ministério da Saúde (BR). Portaria 648 da Atenção Básica de Saúde. Brasília: Ministério da Saúde; 2006. [citado em 6 jun 
Assis WD, et al.

2010]. Disponível em: http://dtr200l.saude.gov.br/sas/ PORTARIAS/Port2006/GM/GM-648.htm.

18. Merhy EE, Franco TB. Por uma composição técnica do trabalho centrada nas tecnologias leves e no campo relacional. Saúde em Debate 2003; 27(65): 316-23.

19. Ayres JRCM. Uma concepção hermenêutica de saúde. Physis 2007; 17(1): 6-10.

20. Pavoni DS, Medeiros CRG. Processos de trabalho na equipe Estratégia de Saúde da Família. Rev Bras Enferm 2009; 62(2): 265-71.

21. Machado K. Experiências inovadoras no ensino da saúde. Rev Radis - Comunic em Saúde 2007; 33(49): 55-7.
22. Merhy EE. Em busca da Qualidade dos serviços de saúde: os serviços de porta aberta para a saúde e o modelo técnicoassistencial em defesa da vida. In: Cecílio LCO, organizador. Inventando a mudança na saúde. São Paulo: Hucitec; 1995. p. 117-60.

23. Starfield B. Atenção primária: equilíbrio entre necessidades de saúde, serviços e tecnologia. Brasília: Unesco/Ministério da Saúde; 2002.

24. Figueiredo GLA, Mello DF. Atenção à saúde da criança no Brasil: aspectos da vulnerabilidade programática e dos direitos humanos. Rev Latino-am Enfermagem 2007; 15(6): 117 I-6.

25. Acioli S. A prática educativa como expressão do cuidado em Saúde Pública. Rev Bras Enferm 2008;61(1): 117-21. 